\title{
ANÁLISIS DEL PAISAJE DEL EMBALSE DE FUNIL (BRASIL) MEDIANTE LA APLICACIÓN DE LA METODOLOGÍA DE FLATRÈS-MURY
}

\author{
Silvério José Coelho \\ Departamento de Agronomía (Universidade Federal de Lavras, Brasil) \\ María Hernández \\ Instituto Interuniversitario de Geografía (Universidad de Alicante, España) \\ José Aldo Alves Pereira \\ Departamento de Ciências Florestais (Universidade Federal de Lavras, Brasil)
}

\section{RESUMEN}

La formación de un embalse para una hidroeléctrica favorece el turismo y el transporte náutico, además de aprovechar los paisajes de su entorno. El estudio visual de estos paisajes puede ser realizado por medio de los puntos de vista horizontales y verticales. El punto horizontal estudia los componentes y los elementos del paisaje. En el vertical, el observador se coloca dentro o fuera del escenario para distinguir zonas en función de la visibilidad y, así, diagnosticar los impactos ambientales, las actividades antrópicas y la belleza del paisaje. El objetivo de este estudio fue proponer modificaciones y ajustes en la metodología de Flatrès-Mury (1984), adaptada por Ayuga Téllez (2001), que posibilitasen diagnosticar la belleza del paisaje y los impactos ambientales en el paisaje del entorno del embalse de la Usina de Hidroeléctrica do Funil en Minas Gerais, Brasil. Los resultados han demostrado que el reajuste y el uso de la metodología, incluyendo el embalse y valorando los parámetros subjetivos como son la amplitud de visión y los concretos como son la ocupación humana, fueron eficientes. Las modificaciones en Amplitud de Visión, Efecto del Relieve y Efecto de Cobertura enriquecieron la metodología, resaltando aspectos no considerados como son la intervisibilidad, el escenario visual, las unidades de paisaje y el efecto espejo del agua, entre otros. La metodología se ha revelado apta para los paisajes agrícolas y naturales, pero sin la capacidad de expresión para los paisajes predominantemente urbanos.

Palabras clave: hidroeléctrica, embalse, paisaje, metodología, calidad visual, FlatrèsMury, puntuación de parámetros, Minas Gerais. 


\begin{abstract}
The formation of a reservoir for a hydroelectric favors the tourism use and the nautical transport, besides taking advantage of the landscapes of its around. The visual study of these landscapes can be realized through horizontal and vertical points of view. The horizontal point of view studies the components and the elements of the landscape. In the vertical one, the observer places inside or out of the scene in order to distinguish zones depending on the visibility and, in this way, to diagnose the environmental impacts, the human activities and the beauty of the landscape. The aim of this research was to propose modifications and adjustments in Flatrès-Mury's methodology (1984), adapted by Ayuga Tellez (2001), which were making possible to diagnose the beauty of the landscape and the environmental impacts in the landscape of hydroelectric do Funil in Mines Gerais (Brazil) arounds. The results have demonstrated that the readjustment and the use of the methodology, including the reservoir and valuing subjective parameters as broad vision and concrete ones as human uses, were efficient. The modifications (broad vision, relief effect and coverage effect) enriched the methodology, highlighting sides not considered as the intervisibility, the visual scene, landscape units and the mirror effect of water, among others. The methodology has been revealed suitable for agricultural and natural landscapes, but without the capacity of expression for urban landscapes.
\end{abstract}

Key words: Hydroelectrics, reservoir, landscape, methodology visual quality FlatrèsMury, punctuation of parameters, Minas Gerais.

\title{
1. Introducción
}

Desde el punto de vista socio-económico la formación de un embalse para una hidroeléctrica establece un impacto positivo relacionado con el desarrollo del turismo y del transporte náutico, además del aprovechamiento del agua y de los variados paisajes del entorno como elementos de ocio. Se consideran también las perspectivas para la irrigación en la producción agrícola, además del consumo y del abastecimiento urbano. Asimismo, en el lugar donde se instala una central hidroeléctrica, el agua pasa a ser el gran elemento de transformación del paisaje, no sólo por la dimensión del embalse sino también por ser un elemento físico con fuerte reclamo estético y simbólico. En este sentido, según Melo Cesar (2000), las grandes extensiones de agua permiten, en cierta forma, una ruptura con los espacios visuales cerrados y continuos, y esa ruptura valora y restituye otra dimensión al paisaje, el vacío. Igualmente, según este autor, el espacio abierto de las superficies acuáticas traduce serenidad, movimiento y vida a la vez que resalta la presencia del cielo como componente fuerte en la percepción del paisaje. También, Litton J.R. (1972) reflexionando sobre la percepción sensorial del paisaje consideró que, al describirla y clasificarla en términos definidos, se señala la naturaleza de las experiencias obtenidas en lugares específicos. En un primer momento, se analiza el tipo de paisaje y, posteriormente, se debe evaluar, por medio de los trazos principales, sus características y calidades.

Actualmente, los estudios de paisajes se pueden hacer subdividiendo el sistema en múltiples componentes, en sistemas parciales. Puesto que un paisaje se constituye a partir de una estructura natural y otra antrópica, el análisis detallado de ambas, así como de sus interrelaciones permite acercarse a una comprensión mayor del sistema denominado paisaje. Según Bertrand (1993) el estudio del paisaje puede tener como foco la perspectiva integrada o sistémica, las perspectivas sectoriales y la perspectiva sensorial (percepción). Esta última es la que intenta permanecer más próxima al significado original del vocablo, aunque presente más dificultad en su conceptualización y sea menos elaborada su metodología. 
Gómez Orea (1985) relata que hay dos puntos de vista para poder estudiar visualmente un paisaje: el horizontal y el vertical. El horizontal permite analizar los componentes y los elementos del paisaje y tiende a la ordenación y a la zonificación del territorio. El vertical, donde el observador se coloca en un punto determinado, «a pie de pista», dentro o fuera del escenario que se analizará, distingue zonas en función de su visibilidad (más allá de sus características visuales), permitiendo diagnosticar impactos ambientales, escenarios de rara belleza y las actividades antrópicas, entre otras.

El objetivo de este estudio fue proponer modificaciones y propuestas en la metodología de Flatrès-Mury (1984), adaptada por Ayuga Tellez (2001), que permitiera diagnosticar la belleza natural y evaluar los diversos impactos ambientales en los paisajes en el entorno del embalse generado por la Hidroeléctrica do Funil - UHE. Ambas tablas aparecen recogidas al final de la presente investigación en un anexo (tabla I y II). La tabla I corresponde a la metodología original, la de Flatres-Mury, la tabla II, a la propuesta por los firmantes de este artículo.

El aprovechamiento hidroeléctrico de Funil fue propuesto para la zona alta del río Grande, cerca del municipio de Lavras-MG. Los primeros estudios son de la década de los 60, mientras que la realización del EIA-RIMA (Estudio de Impacto Ambiental y el Informe de Impacto Medio Ambiental) se realizó en 1991/1992. La licencia para la instalación fue concedida en 2000 y en 2003 se inició su construcción. Con una energía instalada de $180 \mathrm{~mW}$. La UHE-Funil está situada entre en los municipios de Lavras y Perdões, en la región sur del estado de Minas Gerais, incluyendo también los municipios de Bom Sucesso, Ibituruna, Ijací y de Itumirim, siendo Ijací el municipio más afectado (INTERTECHNE, 1992).

\section{Metodología}

La evaluación de los posibles impactos paisajísticos generados por la implantación de una central hidroeléctrica se lleva a cabo a través de la aplicación de la puntuación de parámetros propuesta por Flatres-Mury. La tabla de Flatrès-Mury (1984), adaptada para Ayuga Téllez (2001) (véase anexo, tabla I) se compone de cinco parámetros principales, desagregados en sus respectivas características. Los cinco parámetros suman un total de cien puntos, fraccionados de la siguiente forma:

- Amplitud de visión: 20 puntos,

- Efecto del relieve: 30 puntos,

- Efecto de la cubierta: 30 puntos,

- Efecto de la ocupación humana: 10 puntos y

- Aspecto general (o el efecto de la vecindad): 10 puntos.

Su análisis y consideración resulta fundamental para determinar los impactos ambientales de la implantación de cualquier iniciativa sobre un paisaje. En los apartados sucesivos, se analizan cada uno de estos parámetros, según la metodología propuesta por Flatres-Mury, pero, sobre todo, las modificaciones a ésta, atendiendo a las características particulares del área de estudio.

\subsection{Amplitud de la visión}

En la modificación de la metodología propuesta en esta investigación, la Amplitud de Visión fue desagregada en las características siguientes: intervisibilidad, incidencia visual 
(luminosidad), condiciones de visibilidad y potencial de visualización (Tabla 1). Asignándole una puntuación máxima de 25 puntos totales en la evaluación de las características de los paisajes en el entorno del embalse de la hidroeléctrica do Funil.

Tabla 1

EFECTO DE LA AMPLITUD DE VISIÓN DE LOS PAISAJES EN EL ENTORNO DEL EMBALSE DE LA HIDROELÉCTRICA DO FUNIL EN EL MUNICIPIO DE IJACI, LAVRAS, RELATIVAS A ESE PARÁMETRO

\begin{tabular}{l|c|c|c}
\hline $\begin{array}{l}\text { Intervisibilidad (escenario } \\
\text { visual) }\end{array}$ & $\begin{array}{c}\text { Puro (efectivo) } \\
10-9\end{array}$ & $\begin{array}{c}\text { Intermediario } \\
8-7\end{array}$ & $\begin{array}{c}\text { Bruto } \\
6-5\end{array}$ \\
\hline Clases & Alta & Media & Baja \\
\hline Incidencia visual & 5 & $4-3$ & 2 a 0 \\
Condiciones de visibilidad & 5 & $4-3$ & 2 a 0 \\
Potencial de visualización & 5 & $4-3$ & 2 a 0 \\
\hline
\end{tabular}

Elaboración propia.

La intervisibilidad define el escenario perceptivo real a partir de un punto determinado. Ese parámetro se obtiene combinando una serie de perfiles topográficos con las líneas de vista sobrepuestas a él y convergentes en un observador. La intersección de las líneas de vista con la línea del horizonte delimita los contornos de la «cuenca visual bruta» y las interrupciones de las líneas de la vista con los relieves más pequeños provocan intercesiones visuales, generando zonas de sombra. Cuando la «cuenca visual pura» coincide con la bruta, se tiene un escenario visual compacto, propio de escenarios panorámicos perfectos, en el cual pueden ser vistos, sin obstáculos, todos los objetos contenidos en el escenario y donde es muy difícil ocultar situaciones o impactos (Figura1). La «intervisibilidad», ha permitido identificar en el paisaje tres tipos de escenarios: puro o efectivo, con la puntuación entre 10 y 9; intermedio, con una puntuación entre 8 a 7 y escenario bruto entre 6 y 5 .

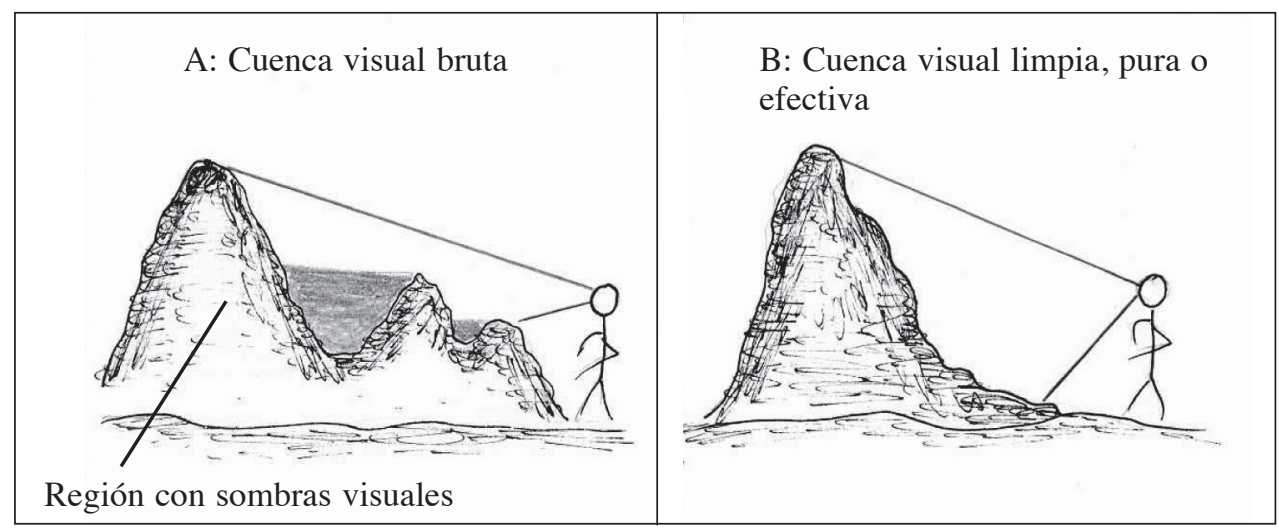

Figura 1. Esquema explicativo de los efectos de la intervisibilidad.

Fuente: Vilá Valenti, 1981. 
Las otras características que componen la amplitud de visión están fuertemente interrelacionadas. La incidencia visual se relaciona directamente con la luminosidad local, las condiciones de visibilidad son un sumatorio de la luminosidad y las condiciones climáticas locales y el potencial de la visualización se corresponde con la posición del observador, añadiendo las condiciones climáticas. Con anterioridad habían sido clasificados en alto, medio y bajo, recibiendo puntuaciones a partir de 5 , de 4 a 3 y de 2 a 0 , respectivamente. En esta investigación, se mantienen esos valores al considerarlos adecuados al área de estudio.

Como en la amplitud de visión es necesario un punto de referencia (lugar donde se ubica el observador), en esta investigación se ha utilizado un barco que se ha ido desplazando a lo largo de las orillas del embalse a una distancia media entre los 300 y 500 metros del borde del embalse, en razón de la facilidad de navegación y de la seguridad. En cuanto a la época de realización de los trabajos de campo, se optó por llevarlos a cabo en el otoño austral (abril) y por la mañana, lo que nos ha permitido condiciones de luminosidad y climáticas (de niebla) marcadas y contrastadas; de modo que la clasificación pudiera incluir todas las características contenidas en la metodología.

\subsection{Efecto del relieve}

En la propuesta metodológica original, el efecto del relieve consideraba las características siguientes: desnivel, declividad, unidades del paisaje, organización de las estructuras y detalles significativos (matices). En el reajuste para este parámetro, atendiendo a las particularidades del área de estudio, fueron consideradas cuatro características: declividad o pendiente (que incluía las respectivas tipologías de relieve), unidades del paisaje, organización de las estructuras y detalles/matices (positivos y negativos), totalizando 25 puntos (tabla 2).

Tabla 2

EFECTO DEL RELIEVE EN LA EVALUACIÓN DE LAS CARACTERÍSTICAS DE LOS

PAISAJES EN EL ENTORNO DEL EMBALSE DE LA CENTRAL HIDROELÉCTRICA

DE FUNIL EN EL MUNICIPIO DE IJACI, LAVRAS, RELATIVO A ESTE PARÁMETRO

\begin{tabular}{cccccccc}
\hline Declividad & $\begin{array}{c}\text { Clases de } \\
\text { relieve }\end{array}$ & Puntos & $\begin{array}{c}\text { Unidades } \\
\text { de } \\
\text { paisaje }\end{array}$ & Puntos & $\begin{array}{c}\text { Organización } \\
\text { de las } \\
\text { estructuras }\end{array}$ & Puntos & $\begin{array}{c}\text { Datos de } \\
\text { Destaque- } \\
\text { Puntuación }\end{array}$ \\
\hline 0 a $10 \%$ & $\begin{array}{c}\text { Plano a } \\
\text { suave } \\
\text { ondulado }\end{array}$ & 2 & 1 & 1 & $\begin{array}{c}\text { Desordenado } \\
\text { Elemento } \\
\text { rectilíneo }\end{array}$ & 1 & -5 a +5 \\
11 a $15 \%$ & Moderado & 4 & 2 & 2 & $\begin{array}{c}\text { Elemento } \\
\text { sinuoso }\end{array}$ & 2 & \\
16 a $20 \%$ & Ondulado & 6 & 3 & 3 & $\begin{array}{c}\text { Elemento } \\
\text { complejo }\end{array}$ & 3 & \\
21 a $45 \%$ & $\begin{array}{c}\text { Fuerte } \\
\text { ondulado }\end{array}$ & 8 & 4 & 4 & $\begin{array}{c}\text { X-elementos } \\
\text { jerarquizados }\end{array}$ & 4 & \\
46 a $100 \%$ & Montañoso & 10 & $>5$ & 5 & $\begin{array}{c}\text { Gran conjunto } \\
\text { estructuras }\end{array}$ & 5 & \\
\hline
\end{tabular}

Elaboración propia. 
En el parámetro «declividad específica de cada área» (en intervalos porcentuales) se inserta el paisaje analizado, asociado a la tipología del relieve, según la clasificación del Instituto Brasileño de Geografía y de Estadística (IBGE). La puntuación creciente de 2 a 10 puntos evaluó respectivamente la variación de relieve entre el valor «ondulado a suave» hasta «montañoso». La metodología base para este estudio recomienda evaluar los parámetros y sus características tanto cuanto sea posible «in loco», es decir, en el lugar, que en este trabajo implicó la dificultad para determinar la pendiente en el entorno del embalse. Para ello, se utilizó un clinómetro tipo Abney, dispositivo de precisión relativa en trabajos de campo y que además, en este caso, permitió hacer una lectura acertada, debido a la formación de ondas con el desplazamiento del barco, hecho que coincidió con la lectura del dispositivo. Posteriormente, se hizo una calibración comparativa de las lecturas conseguidas con la información contenida en El Plan Ambiental de la Conservación y del Uso del Entorno del depósito artificial del la UHE-Funil, publicada en el artículo «Caracterización de los sectores definidos en el área de Entorno de la UHE-Funil», que incluye el tipo de relieve para cada sector. El sector II, situado en gran parte en el municipio de Ijaci, posé el $15 \%$ de relieve plano, el $55 \%$ de relieve ondulado y el $30 \%$ de relieve montañoso. Las relaciones, desde el punto de vista porcentual, entre declividad-tipo de relieve son: 0-3\% (relieve plano); 3-8\% (relieve suave ondulado); $8-20 \%$ (relieve ondulado) y 20-45\% (relieve fuerte ondulado). Las evaluaciones realizadas con el clinómetro fueron entonces comparadas con estas de clase de relieve respectivamente, disminuyendo así los posibles errores circunstanciales.

En el parámetro «unidad de paisaje», entendido como la diferenciación fisiográfica basada en la calidad homogénea de los factores visuales que definen el paisaje, se propone una puntuación que varía de 1 a 5 . Esta puntuación favoreció la diferenciación de un número mayor de unidades del paisaje en un área, haciéndolo más interesante visualmente. En este trabajo, se consideró siempre el espejo del agua formado por el embalse como unidad de paisaje y las demás unidades fueron las configuradas por los aspectos fisiográficos de las líneas del relieve, por la vegetación o por el uso antrópico. El cielo, considerado como una unidad del paisaje en la evaluación visual, no fue cuantificado como tal en este trabajo.

El siguiente ítem considerado fue «organización de las estructuras». En él, un relieve con ondulaciones se debe considerar como elemento positivo en el paisaje, porque facilita la organización de las estructuras, además de posibilitar la visualización de un número mayor de unidades del paisaje. En la metodología, esta organización fue evaluada en relación a varios elementos y componentes, así como la jerarquía existente entre ellos, variando desde «desordenadas» hasta «gran conjunto de estructuras» con una puntuación creciente respectivamente de 0 a 5 puntos.

Los detalles o los matices, negativos o positivos, fueron puntuados respectivamente en una escala de $-5 \mathrm{a}+5$, considerando, incluso si fuera posible, que en el mismo paisaje existieran uno o más detalles, tanto negativos como positivos. En ese caso, la adición de los dos daría una puntuación final. Los procesos erosivos intensos, y que se destacaron en el paisaje, fueron puntuados negativamente por relacionarse con cuestiones ecológicas. Un lego, sin embargo, podía perfectamente no tener esta percepción técnica y evaluar el paisaje como hermoso, en virtud del contraste establecido entre los colores de la tierra erosionada, del agua y del verde de la vegetación. Hay que considerar, en ese caso que la percepción del paisaje es un proceso cultural, susceptible, por lo tanto, de ser asimilado.

\subsection{Efecto de cubierta}

En la propuesta metodológica original, el parámetro «efecto de la cubierta» consideraba los siguientes ítem: la presencia o no del agua, del aspecto salvaje de la vegetación, 
de la variedad de masas (biodiversidad), de la armonía de las estructuras y de un cierto detalle de destaque y/o matiz. En el reajuste realizado para ese parámetro, la presencia del agua fue sustituida por la calidad del agua, evaluada por medio del índice de turbidez. El aspecto salvaje de la vegetación fue sustituido por el porcentaje de la cubierta vegetal con fragmentos vegetales y los otros factores fueron mantenidos (Tabla 3). El valor máximo asignado a este concepto en la evaluación de las características de los paisajes en el entorno del embalse de la Central Hidroelétrica do Funil fue de 30 puntos.

Tabla 3

EFECTO DE LA CUBIERTA Y DE LA SUPERFICIE EN LA EVALUACIÓN DE LAS CARACTERÍSTICAS DE LOS PAISAJES EN EL ENTORNO DEL EMBALSE DE LA CENTRAL HIDROELÉTRICA DO FUNIL EN EL MUNICIPIO DE IJACI, LAVRAS

\begin{tabular}{|c|c|c|c|c|c|c|c|c|}
\hline $\begin{array}{l}\text { Índice de } \\
\text { Turbidez } \\
\text { (NTU) }\end{array}$ & Nota & PCV & Nota & VM & Nota & HE & Nota & $\begin{array}{c}\text { Datos de } \\
\text { Destaques- } \\
\text { Puntuación: }\end{array}$ \\
\hline $0-10$ & $5-4$ & $>$ el $75 \%$ & 10 & $>5$ & 5 & Ajuste total o & 5 & $-5+\operatorname{los} 5$ \\
\hline $11-40$ & 3 & $5075 \%$ & 8 & 4 & 4 & perfecto & & \\
\hline $41-100$ & 2 & $2550 \%$ & 6 & 3 & 3 & Acercamientos del & & \\
\hline \multirow{4}{*}{$>100$} & $0-1$ & $1025 \%$ & 4 & 2 & 2 & ajuste & & \\
\hline & & $<\operatorname{el~} 10 \%$ & 2 & uniforme & 0 & de (normal) & 4 & \\
\hline & & Puntual & 1 & & & $\begin{array}{l}\text { Un sector } \\
\text { aberrante }\end{array}$ & $1-2-3$ & \\
\hline & & & & & & Desordenado & 0 & \\
\hline
\end{tabular}

Unidad de NTU = de Nephelemetric Turbidit

$\mathrm{PCV}=$ porcentaje de la cubierta vegetal con fragmentos vegetales

$\mathrm{VM}=$ variedad de masas

HE = armonía de las estructuras

Elaboración propia.

El elemento «calidad del agua» fue evaluado mediante el índice de turbidez, por medio de unidades nefelométricas de turbidez (NTU). En la determinación de este índice, se ha buscado establecer una relación entre el «efecto de espejo» ejercido por la lámina de agua del embalse y los diversos elementos que existen en su orilla. Los intervalos fueron establecidos tomándose como referencia el límite máximo de turbidez para las aguas potables (5.0 NTU). Así, los índices más bajos de turbidez implicarían una transparencia mayor del agua, con reflejos más nítidos de los elementos del entorno inmediato. Para la determinación de ese índice, las muestras de agua fueron recogidas en botes del polietileno de $250 \mathrm{ml}$, a una profundidad media de 30 centímetros, en diez puntos de muestreo distintos, siendo transportadas posteriormente para un análisis específico en un turbidímetro AP 2000 - portátil en el laboratorio del Departamento de Suelos de la Universidad Federal de Lavras, Minas Gerais.

Para determinar el parámetro «aspecto salvaje», se evaluó el porcentaje de la cubierta vegetal natural (PCV) en el paisaje, valorando cuantitativamente paisajes con fragmentos significativos y aquellos en los que ésta ocupará más del 75\% del área. La evaluación de la 
relación aspecto salvaje/fragmento de bosque se realizó de acuerdo con la escala del paisaje en el ámbito de la fotografía y considerándose las fracciones de superficies cubiertas por bosque, establecidas por la tabla.

En la variedad de masas, parámetro relacionado con el anterior, se ha evaluado visualmente y cuantitativamente los diversos volúmenes, colores y texturas de la vegetación, como indicativo de la diversidad vegetal existente, puntuando más los paisajes con una variedad más grande. En el análisis de las fotografías, la variedad de masas fue evaluada según diversas texturas y coloraciones perceptibles en cada foto, mientras la armonía de las estructuras fue evaluada de acuerdo con las líneas más marcadas del relieve, sumando los elementos verticales que en ellos se insertaron.

Por último, para determinar la «armonía de estructuras», en este artículo, se ha procurado evaluar la forma como las estructuras del paisaje se interrelacionan; intentando determinar su grado de ajuste, en un universo que varía desde un ajuste total o perfecto, hasta la posibilidad de sectores aberrantes o desordenados. También se ha considerado la posibilidad puntuar los detalles o relieves positivos o negativos en el paisaje.

\subsection{Efecto de la ocupación humana y de la evaluación global/aspecto general}

Estos dos últimos parámetros fueron mantenidos de la propuesta metodológica primigenia sin alteración o modificación alguna. Para su análisis, están agrupados en la tabla número cuatro. La valoración máxima de ambos factores en la valoración de las características de los paisajes en el entorno del embalse de la Usina Hidroelétrica del Funil en el municipio de Ijaci, Lavras asciende a 20 puntos.

Tabla 4

EFECTO DE LA OCUPACIÓN HUMANA Y DEL ASPECTO GENERAL EN LA

VALORACIÓN DE LAS CARACTERÍSTICAS DE LOS PAISAJES EN EL ENTORNO

DEL EMBALSE DE LA HIDROELÉCTRICA DE FUNIL EN EL MUNICIPIO DE IJACI, LAVRAS, CONCERNIENTE A ESTOS PARÁMETROS

\begin{tabular}{lcc}
\hline Efectos de la ocupación humana & Detalles o prominencias & Total \\
\cline { 2 - 3 } & Positivos: hasta $10+$ & Negativas: hasta $10-$ \\
Evaluación global: efecto del \\
$\begin{array}{l}\text { aspecto general (el paisaje en su } \\
\text { sistema) }\end{array}$ & hasta 10 puntos + & hasta 10 puntos - \\
\hline
\end{tabular}

Elaboración propia.

En el parámetro «ocupación humana», se trata de evaluar los detalles o las repercusiones relacionados con la ocupación antrópica, tanto desde del punto de vista agropecuario, urbano o turístico, puntuando positivamente los aspectos que se encuentran en armonía con el paisaje y, de forma negativa, los que no. Así, se ha considerado desde la ausencia de cualquier intervención humana, hasta los elementos antrópicos que ya existían y los generados con la formación del embalse. Fueron identificadas las áreas de cultivo, construcciones diversas, las granjas, las instalaciones para la cría de ganados y otros, además de las distintas formas de ocupación de las orillas del embalse posteriores a la construcción de la UHE-Funil. Concretamente, los diferentes elementos identificados en el paisaje, tanto negativos como positivos, han sido puntuados de 0 a 10 , con signo negativo (-) los 
primeros y positivo (+) los segundos. El total es resultado de la adición de los dos. En este parámetro, se ha buscado también valorar más los espacios menos cultivados y que habían preservado la vegetación natural.

En el epígrafe «evaluación global del paisaje» se ha buscado evaluar el efecto del aspecto general, agregándolo a la evaluación técnica de los parámetros y de las características consideradas en los parámetros anteriores, así como la manifestación del subsistema extra-mental del proceso perceptivo del conjunto, como expresión fenotípica de un área determinada. De esta forma, fue posible caracterizar cada paisaje como interesante o no, y además permitir que fuera expresada la opinión personal «me gusta, no me gusta». Es decir, se da cabida a valoraciones más subjetivas, frente a estimaciones de carácter más objetivo-científicas en los anteriores.

El item «total general» está constituido por la adición de los cinco parámetros evaluados: amplitud de visión, efecto del relieve, superficie y efecto de la cubierta, efecto de la ocupación humana y efecto del aspecto general. Pone de manifiesto el estado general del paisaje puntuado. Permitiendo, en una fase posterior, proponer medidas para, bien, intentar minimizar los procesos negativos evidencias, bien potenciar las actuaciones presentes para conservar puntuaciones positivas.

\section{La implementación de la metodología propuesta en el área de estudio}

La metodología propuesta se ha aplicado en el área de estudio señalada en epígrafes anteriores, concretamente en la Introducción. El objetivo era valorar las repercusiones paisajísticas derivadas de la génesis de un embalse. Se ha realizado, tomándose como base la estructura cóncava formada por el embalse y el relieve a su alrededor, a través de la identificación de los diversos paisajes existentes en el entorno del embalse. Los criterios para la elección de los paisajes incluyeron los escenarios visualmente agradables, aquéllos con elementos de belleza significativos, las áreas de ocupación humana impactante, los fragmentos de bosque, entre otros.

En la evaluación de las características del paisaje, se utilizó un barco para cubrir visualmente el embalse en el entorno de la municipio de Ijaci, detectándose y registrándose con una cámara fotográfica PENTAX - SFX las diversas escenas (paisajes) allí existentes. Cada escena fue relacionada con una posición geográfica, usando un dispositivo GPS (sistema de posicionamiento global). Posteriormente, los registros fotográficos fueron descargados en el ordenador e identificados según una planilla de campo. Los lugares fotografiados fueron identificados localmente por medio de una referencia específica en relación al uso dominante (antrópico o natural), complementando, así, la planilla de campo.

Se realizaron un total de 85 registros fotográficos, que cubrían en su totalidad las diferentes tipologías de paisaje existentes en el área de estudio. Con los datos relativos a los paisajes, recogidos en los trabajos de campo, se compuso una tabla específica que contenía los siguientes epígrafes: el número de la orden, localización, coordenadas GPS, el clinómetro, recolecta del agua, elementos de identificación del paisaje, secuencia y comentarios. Todos los paisajes fotografiados fueron sometidos al reajuste de la metodología de Flatrès-Mury (1984), adaptada para Ayuga Téllez (2001) (Anexo, Tabla I y II).

En la evaluación final de cada uno de los ochenta y cinco paisajes seleccionados, se ha considerado la mayor y menor puntuación para cada uno de los cinco parámetros evaluados: amplitud de visión, efecto del relieve, efecto de la cubierta, efecto de la ocupación humana y aspecto general. El análisis concluye distinguiendo los factores determinantes, tanto para la mayor como para la menor puntuación que han sido aplicados en cada uno de las escenas objeto de puntuación de parámetros. 


\section{Principales resultados y propuestas de la implementación de la metodología en el área de estudio}

Los paisajes fotografiados y clasificados, según la metodología de Flatrès-Mury, se presentan agrupados en los cinco parámetros que ésta considera: amplitud de la visión, relieve, cubierta vegetal y ocupación humana. Dada la imposibilidad de reproducir los ochenta y cinco paisajes evaluados, se han seleccionado algunos de ellos, concretamente, once, que corresponden, a los paisajes de mayor y menor valor obtenido en la aplicación de la tabla de puntuación de paisajes.

\subsection{Amplitud de visión}

El paisaje con la mayor puntuación (22/25) aparece reproducido en la figura número dos. Corresponde a la Comunidad de la Serra, con la Serra do Jaci al fondo (Coordinadas UTM: $X=509579,181 \mathrm{~m}$. E.; Y = 7657860,771 m. N.). Los factores que definen a este paisaje son: una cuenca visual pura o efectiva, promedio de la incidencia visual (luminosidad) elevado y unas condiciones medias la visibilidad y potencial de la visualización alta y/o media.

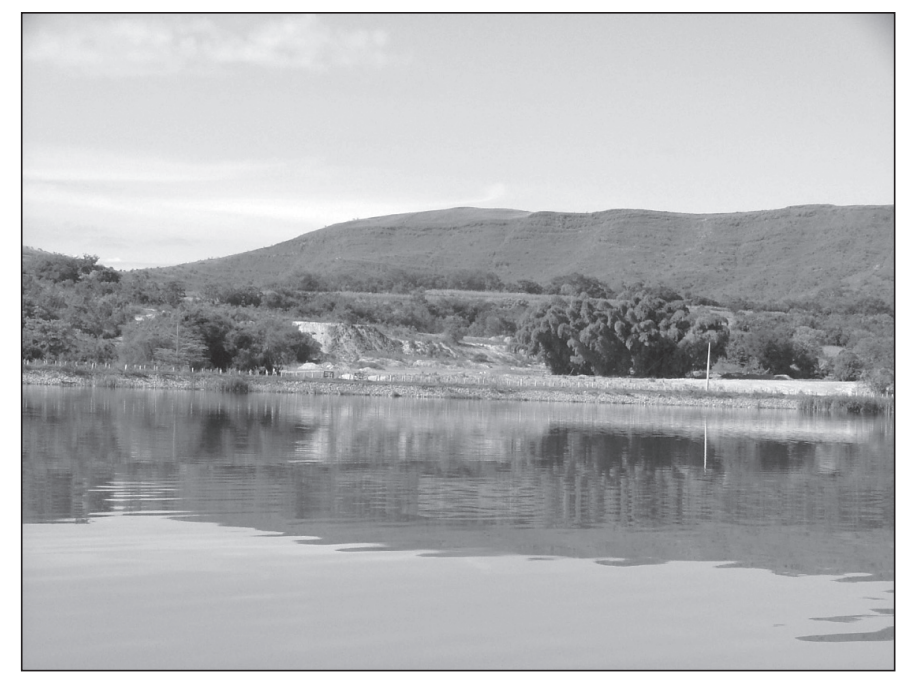

FIGURA 2. Paisaje con la puntuación mayor del parámetro «amplitud de visión» en el entorno del embalse de la UHE Funil, en la municipio de Ijaci, Lavras, MG.

En contraposición, el paisaje que ha obtenido una menor puntuación (13/25) en este parámetro (figura 3) se localiza en la comunidad do Barreiro (Coordinadas UTM: X = 501246.260 m. E.; Y los =7662536,801m. N.). Los elementos determinantes de esa puntuación baja son: una cuenca visual bruta, una incidencia visual, en términos de luminosidad, baja y unas condiciones de visibilidad también bajas y un potencial de visualización, medio. Es decir, es uno de los paisajes cuya perspectiva es bastante complicada y, por tanto, su posible potencial turístico, bajo. 
Una de las principales conclusiones obtenidas en la puntuación de este parámetro es que la «intervisibilidad», que define el escenario perceptivo real desde el punto donde se coloque un observador, es el elemento que influye más en la evaluación de la amplitud de visión, por ser una característica física, geográfica. En este sentido, la luminosidad, las condiciones climáticas y la posición del observador son oscilantes y puntuales, pudiendo variar, y, consiguientemente, también la valoración final de un paisaje determinado.

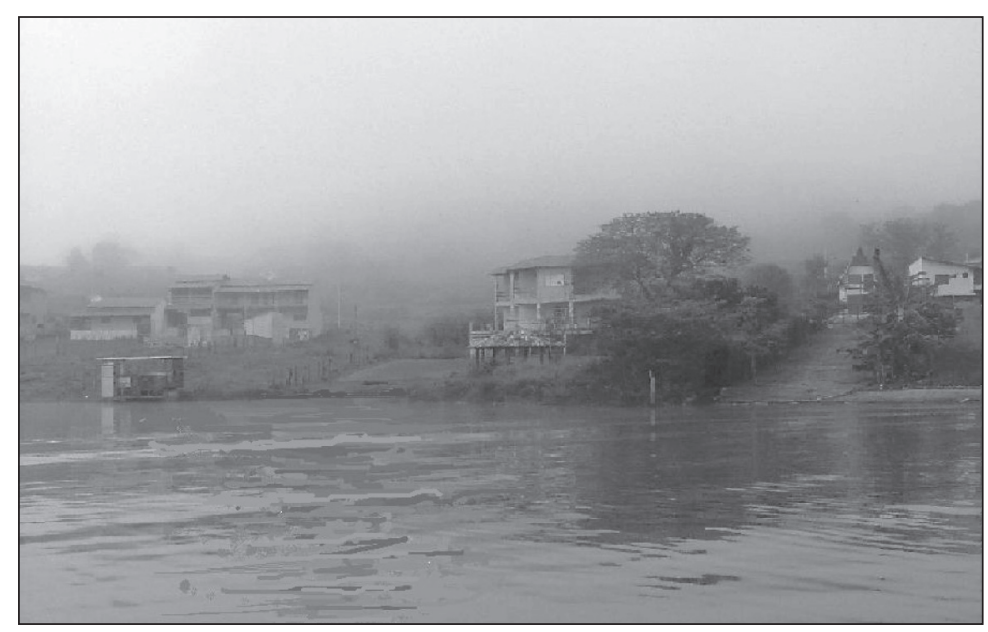

FIGURA 3. Paisaje con puntuación baja para el parámetro «amplitud de visión» en el entorno del embalse de la UHE Funil, en la municipio de Ijaci, Lavras.

\subsection{Efecto del relieve}

El paisaje que obtuvo una mayor puntuación (21/25) en este parámetro fue el que corresponde a la Serra do Jaci, el fundo y el bosque de la hacienda Cley Fonseca, a la derecha (figura 4), que corresponde a las coordenadas UTM: X = 509404.342 m. E.; $\mathrm{Y}=7659653.439 \mathrm{~m}$. N. Los factores determinantes de esta valoración fueron: relieve fuerte ondulado a ondulado, de 3 a 4 puntos en el epígrafe unidades del paisaje, con subunidades, unos elementos jerarquizados sinuosos y un elemento de relieve positivo (Serra do Jaci).

En contraposición, el paisaje con menor puntuación (4/25) corresponde a la zona agrícola de la comunidad de Serra (fig 5), (UTM coordenada: X=509682.997 m. N. y 7659049.692 $\mathrm{Y}=\mathrm{m}$. N.). Los elementos que determinan una puntuación tan baja, son: relieve llano a suave o moderadamente ondulado, de 3 a 4 unidades del paisaje, con subunidades, presencia de elementos rectilíneos y proceso erosivo acentuado con relieve negativo.

La presencia de relieve de cierta entidad y la sinuosidad de las líneas se convierten en los elementos más valorados en este parámetro. La ausencia de altitud y, de ciertas pendientes, unido a la existencia de líneas rectas determinadas por los usos antrópicos, que introducen geometrización en el paisaje, y la aparición de elementos que evidencien procesos erosivos, entendidos en términos de destrucción de paisaje, son, en cambio, valorados negativamente. 


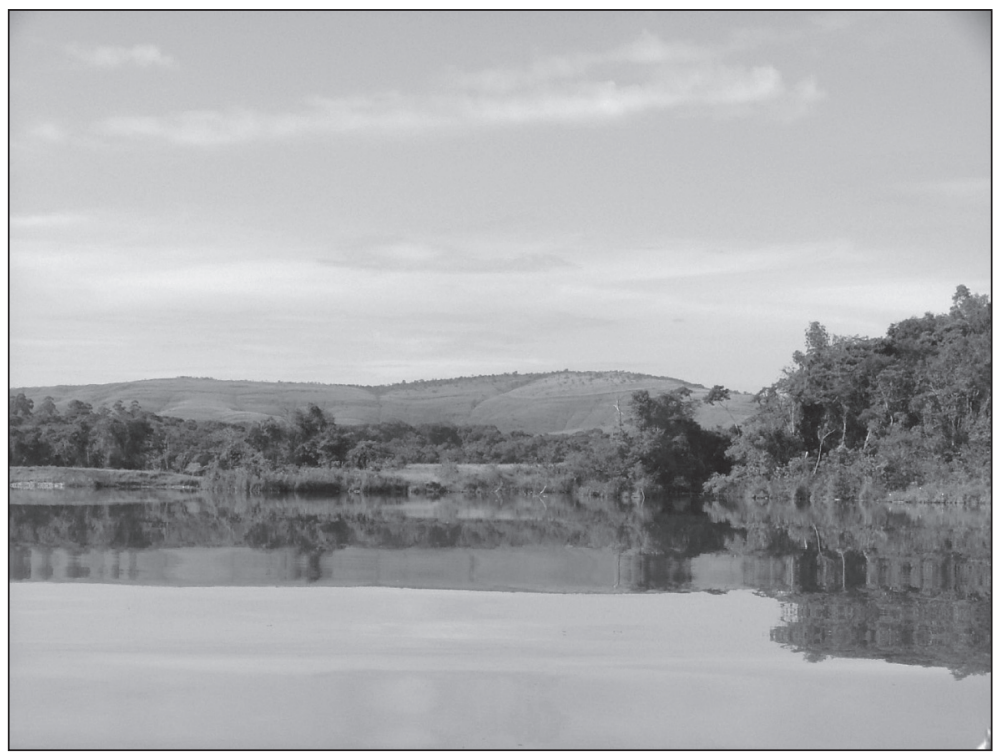

FIGURA 4. Paisaje con la puntuación mayor para el parámetro «efecto del relieve», en el entorno del embalse de la UHE Funil, en la municipio de Ijaci, Lavras.

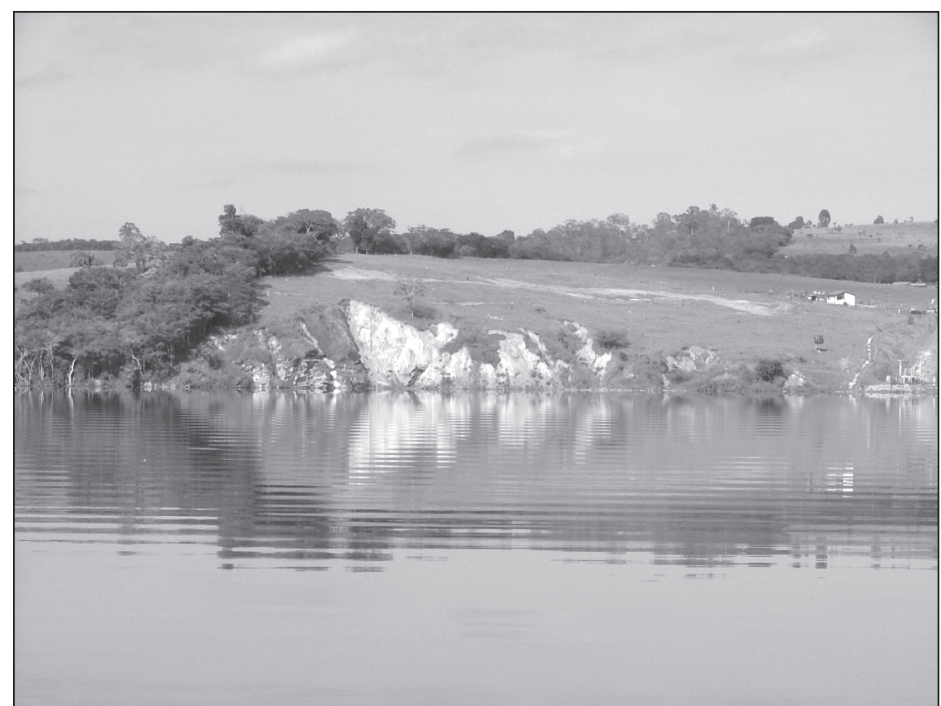

FIgURA 5. Paisaje con menor puntuación para el parámetro «efecto del relieve», en el entorno del embalse de la UHE Funil, en la municipio de Ijaci, Lavras. 


\subsection{Superficie y efecto de la cubierta}

Este parámetro puntúa, por un lado, la superficie, en este caso, la lámina de agua y, por otro, la cubierta vegetal. Con respecto al primero, los índices de turbidez encontrados varían entre 6.59 y 9.96 y fueron evaluados como excelentes, consiguiendo la puntuación de 5 puntos, ya que todos se sitúan por encima del valor 5, que corresponde a aguas aptas para el consumo. Ello determina que la superficie sea considerada, en gran medida, como un valor neutro, ya que no permite establecer grandes diferencias entre los diferentes paisajes. Eso, si, se considera un valor altamente positivo, dada su calidad y el efecto de atracción que desempeña. Será, por tanto, la cubierta vegetal el parámetro que permita diferenciar y establecer contrastes entre los paisajes evaluados.

Teniendo en cuenta, esas precisiones, el paisaje con mayor puntuación (28/30) corresponde al proyecto para la recuperación del bosque de ribera desarrollado por la Ufla (figura 6) (UTM coordenada: $\mathrm{X}=509223.297 \mathrm{~m}$. y 7660122.550 Y = m. N.). Los factores determinantes en esa valoración altamente positiva son: la relación aspecto salvaje/fragmento del bosque, la variedad significativa de masas (biodiversidad), el ajuste normal, en términos de naturalidad, de las estructuras y la presencia de un elemento particular o de un detalle positivo como es el proceso de la recuperación del bosque de ribera.

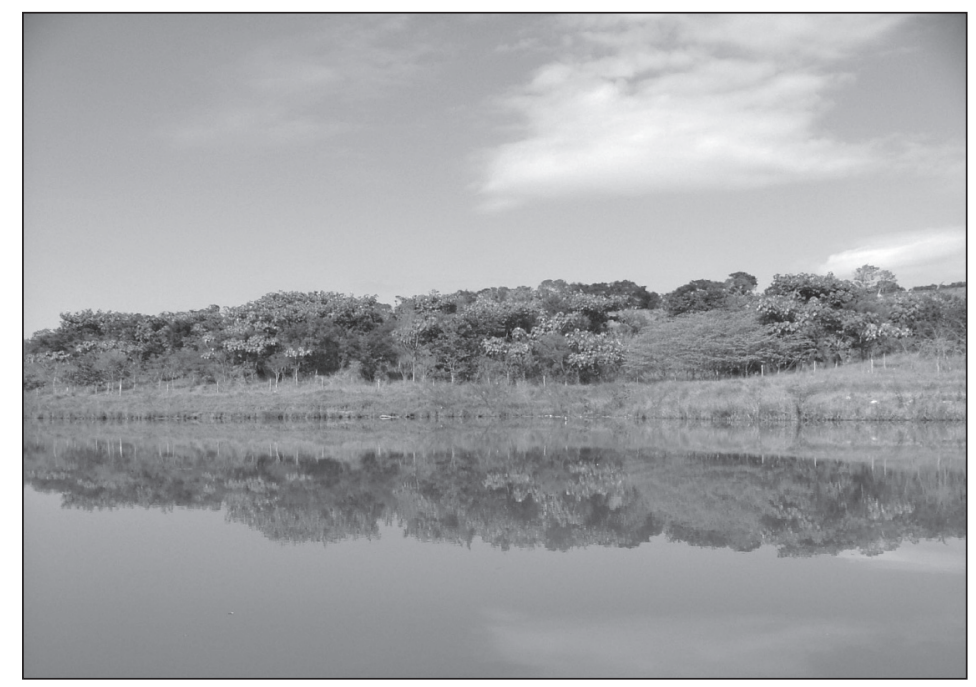

FIgURA 6. Paisaje con la puntuación mayor para el parámetro «efecto de la cubierta», en el entorno del embalse de la UHE Funil, en el municipio de Ijaci, Lavras.

El paisaje con la menor puntuación en este epígrafe corresponde a la figura número 7, en el que el elemento dominante son los procesos erosivos (coordenadas UTM: $X=511663$, $871 \mathrm{~m}$. E.; Y $=7657714.733 \mathrm{~m} \mathrm{~N}$.). Los factores determinantes de esa baja valoración son la ínfima, por no decir nula, relación entre el aspecto salvaje/fragmento de bosque, la escasa variedad de masas, la presencia de un sector o subunidad paisajística aberrante (entendido como proceso que genera fuerte rechazo), y un detalle negativo (erosión). 


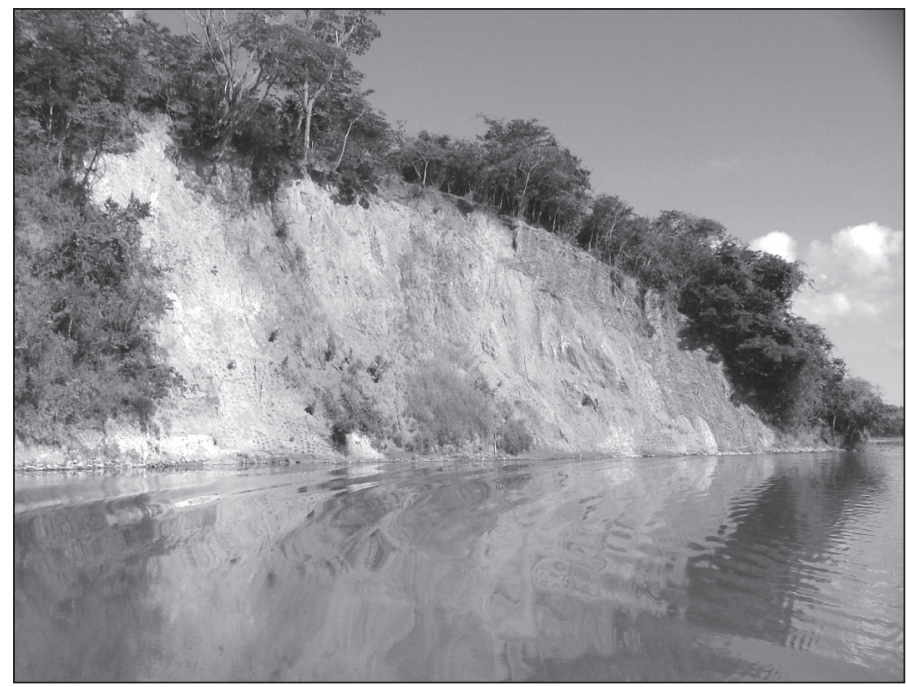

FIGURA 7. Paisaje con menor puntuación para el parámetro «efecto de la cubierta», en el entorno del embalse de la UHE Funil, en el municipio de Ijaci, Lavras, MG.

Dado el interés y el atractivo que revisten las masas de agua, pero a la vez, el valor homogéneo que en el ámbito de estudio tiene, dada su calidad (turbidez) y su carácter predominante, ya que se han evaluado los paisajes ribereños del embalse, se incluye el paisaje con «efecto espejo perfecto» puntuado con el máximo valor (5) para la calidad del agua $(\mathrm{NTU}=9.06)$. Se localiza (figura 8 ) en la propiedad rural de Don Tonico Leôncio (coordenadas geográficas UTM: $X=509033.788 \mathrm{~m} \mathrm{E} ; \mathrm{Y}=7660969.018 \mathrm{~m} \mathrm{~N}$ ). Es la luminosidad, la calidad y el efecto lumínico del agua dada su gran transparencia la que determina la atracción ejercida por esta unidad paisajística.

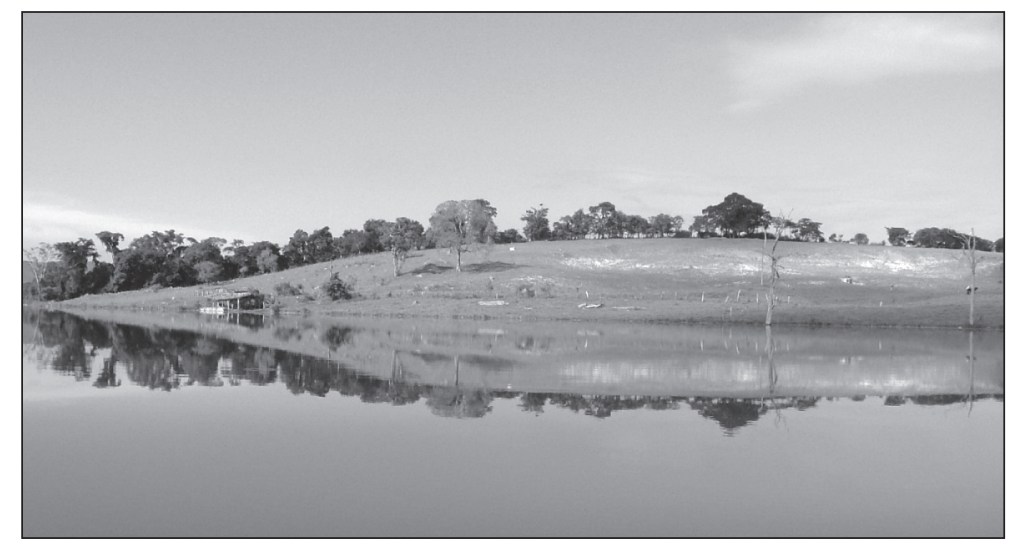

FIGURA 8. Paisaje con el «efecto espejo perfecto», puntuada en el entorno del embalse de la UHE Funil, en el municipio de Ijaci, Lavras, MG. 
Las masas de vegetación, su biodiversidad y, en general, los elementos naturales de los paisajes fueron los elementos más valorados en la puntuación de parámetros de este parámetro. En contraposición, aquellos elementos que indicasen degradación, como pueden ser los procesos erosivos, fueron penalizados. El valor estético y sensorial del agua fue, también, muy valorado. La sensación de tranquilidad y belleza a él asociados justifican las altas puntuaciones obtenidas en los paisajes objeto de estudio, especialmente en los que la refracción de la luz es elevada.

\subsection{Efecto de la ocupación humana}

Los paisaje con las puntuaciones más elevadas (8/10 y 7/10) aparecen representados en la figura número 9, que se localizan en la comunidad del Barreiro (coordenadas geográficas UTM: X = 501246.260 m. E.; Y los = 7662536,801m. N.). El factor determinante de tal puntuación fue que los elementos antrópicos se encontraban en armonía con el paisaje, es decir, que los usos humanos no generaban fuertes impactos en el entorno. En la comunidad del Barreiro, la formación del embalse afectó una propiedad rural cuya ocupación se realizó de forma discreta.

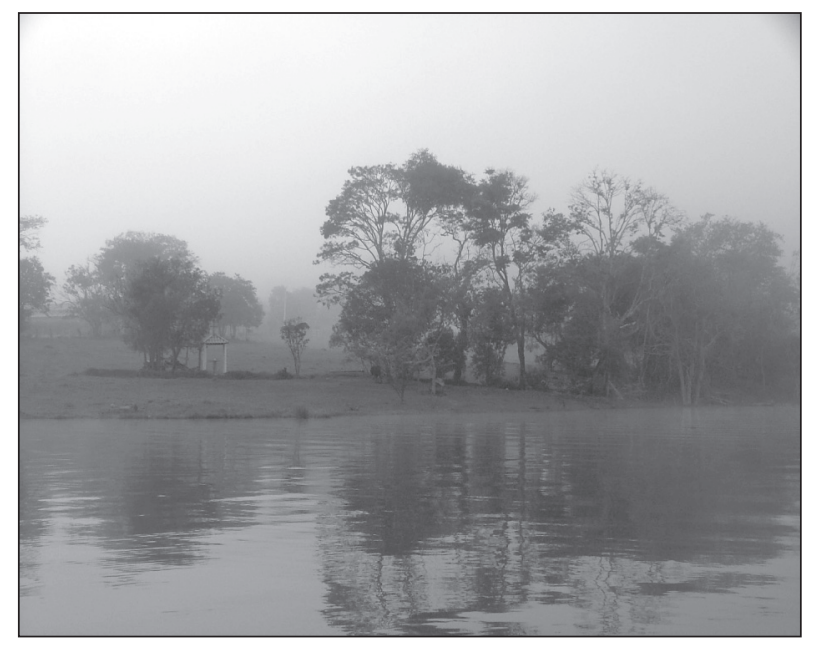

Figura 9. Paisaje con mayor puntuación en el parámetro «efecto de la ocupación humana» en el entorno del embalse de la UHE Funil, en el municipio de Ijaci, MG.

El paisaje con menor puntuación $(-8,-10)$ se obtuvo en el correspondiente a Chacreamento en el Barreiro (figura 10) (coordenadas geográficas UTM: X = 501246.260 m. E.; Y $=7662536,801 \mathrm{~m}$. N.). Los factores determinantes de una puntuación tan baja (valores negativos) se vincula a la transformación paisajística y de los usos tras la creación del reservorio del embalse. La formación del embalse fomentó la construcción de edificaciones que, generaron fuertes afecciones paisajísticas, ya sea por los colores, por la proximidad de las construcciones tanto en el borde como entre ellas, y por su volumetría (número de pisos). 


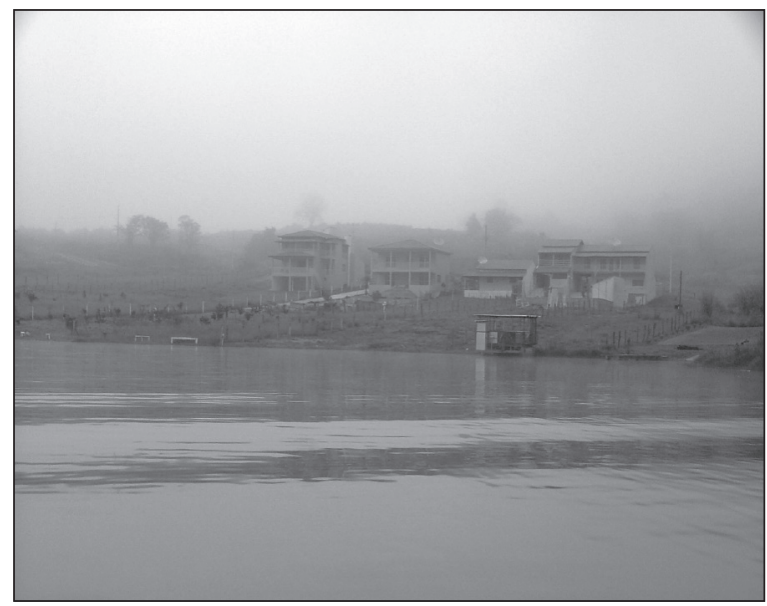

FIGURA 10. Paisaje con menor puntuación en el parámetro «efecto de la ocupación humana» en el entorno del embalse de la UHE Funil, en el municipio de Ijaci, MG.

La integración de los usos antropogénicos en el paisaje fue el factor fundamental a la hora de puntuar el efecto de la ocupación humana en el entorno del embalse do Funil. Las actividades que prestaron escasa atención a su inserción en el entorno, especialmente las aparecidas tras la creación del reservorio de agua, fueron altamente penalizadas, además de generar un cierto rechazo por parte de la población.

\subsection{Efecto del aspecto general}

El efecto del aspecto general fue el último parámetro considerado. El paisaje que obtuvo una mayor puntuación (8/10), identificado en este artículo como la figura 11, se localiza en la comunidad de la Serra do Jaci, al fondo (coordenadas geográficas UTM: X = 509579,181m. E.; Y = 7657860,771 m. N.). Los factores determinantes de esa puntuación tan favorable fueron la amplitud de la visión debido a la propia configuración del relieve que proporcionaba unas cuencas visuales puras, la presencia de fragmentos vegetales que proporcionaban una importante masa verde, además de una biodiversidad importante, la presencia del espejo del agua con unos índices de refracción altos y la baja ocupación humana. Es decir, sintetizaba algunos de los elementos que obtenían las puntuaciones más elevadas en los otros cuatro parámetros, como son la naturalidad del paisaje y el valor estético del agua. La suma de ellos permitía obtener una valoración general muy favorable.

El paisaje con menor puntuación en este parámetro $(-5,-3)$ aparece recogido en la figura número 12, que corresponde al municipio de Ijaci, con la fábrica de cemento al fondo (coordenadas geográficas UTM: X = 512927,977 m. E.; Y = 7658311,220 m. N.). Los factores determinantes de ese reducido valor, vino determinado por la baja amplitud de visión al existir numerosos obstáculos que rompían la cuenca visual, las inserciones antrópicas entre las que destaca la fábrica de cemento, que generaba un cierto impacto visual, y el pequeño embalse, que al igual que la fábrica de cemento, produce cierto impacto visual; acrecentados ambos por la reducida cuenca visual, que acentuaba cualquier elemento, bien en términos positivos o negativos. En este caso concreto, los segundos. 


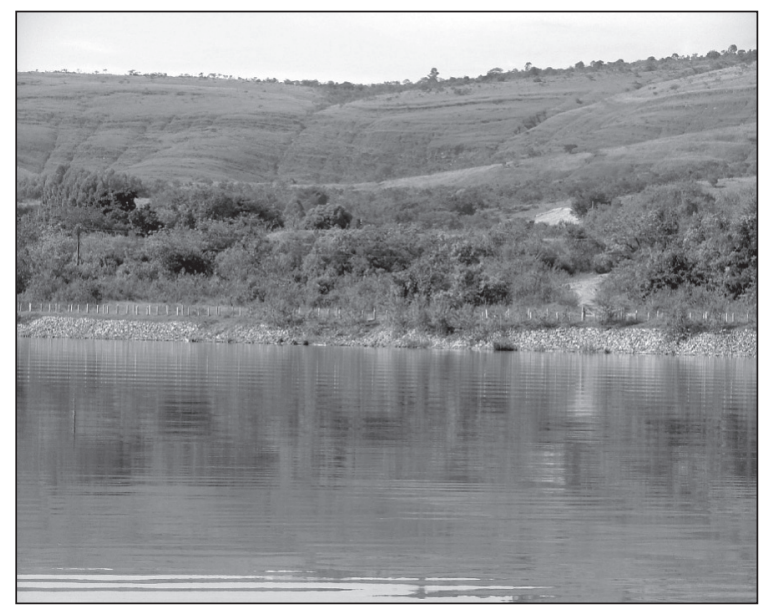

Figura 11. Paisaje con la puntuación más elevada para el parámetro «aspecto general» en el entorno del embalse de la UHE Funil en el municipio de Ijaci, MG.

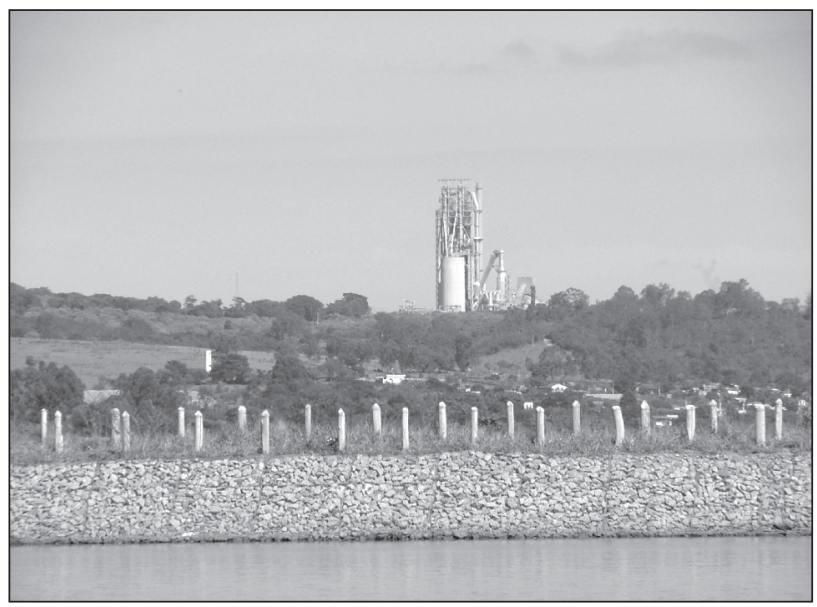

FIGURA 12. Paisaje con menor puntuación para el parámetro «aspecto general» en el entorno del embalse de la UHE Funil en el municipio de Ijaci, MG.

\section{Conclusiones}

El reajuste y el uso de la metodología de Flatrès-Mury (1984) en el estudio de los paisajes en el entorno del embalse de la UHE del Funil en el municipio de Ijaci, se ha mostrado eficiente por incluir el embalse, más concretamente la lámina de agua como unidad paisajística y, también para permitir valorar con parámetros subjetivos como la amplitud de visión (luminosidad, visibilidad), pero también concretos, como el relieve, el efecto de la cubierta y la ocupación humana, entre otros. 
Las modificaciones realizadas en parámetros amplitud de visión, efecto del relieve y el efecto de la cubierta ha enriquecido la metodología, al adaptarla al área de estudio, resaltando aspectos hasta entonces no considerados, como la intervisibilidad, la escena visual, la variedad del relieve, las unidades del paisaje, el índice de turbidez y el efecto espejo del agua. Elementos ellos, particulares, de un paisaje generado por la construcción de un embalse y que, en la mayoría, de los paisajes carecen de peso específico. Significativo resulta el efecto «lámina de agua» generado por la refracción de la luz sobre el agua embalsada.

Con parámetros cualitativos, a veces subjetivos, la evaluación visual de paisajes es útil para detectar desde escenas de una belleza extraordinaria (altamente valorada por potenciales turistas, pero también por los propios habitantes del lugar) hasta los impactos ambientales localizados y no detectados por imágenes del sensor remoto de baja resolución, pudiendo constituirse en una herramienta más en el proceso del planeamiento. Herramienta valiosa, ya que además de las evaluaciones científicas, incluye apreciaciones derivadas de la percepción subjetiva de la población, que, en ocasiones pueden carecer de valor intelectual, pero no emotivo y este último es, muchas veces, el que moviliza a la población.

A pesar de presentar los parámetros cualitativos, sujetos a los factores culturales y a los procesos extra-mentales (percepción), la metodología adoptada se mostró eficiente no sólo para la evaluación de un paisaje específico, sino además en la evaluación comparativa de varios paisajes. La comparación de los valores obtenidos, y sobre todo, la reiteración de determinados resultados, permitía deducir las posibles causas que determinaban el aprecio o el rechazo por un paisaje, que desde, parámetros estrictamente científicos, no presentaban grandes diferencias.

La metodología usada y reajustada se reveló indicada principalmente para los paisajes rurales (agrícolas o no) y para los paisajes naturales, perdiendo, sin embargo, la capacidad de expresión y poder sensorial para los paisajes eminentemente urbanos, sin espacios verdes y elementos naturales.

El uso de la metodología «in situ» puede ser más eficiente cuando se compara con su uso en los paisajes registrados en fotografías. Estas últimas, sin embargo, permiten establecer escalas, es decir, los límites geográficos para el paisaje evaluado, facilitando así el proceso de evaluación. La utilización de ambos métodos de trabajo proporciona los resultados más valiosos.

\section{Referencias bibliográficas}

AYUGA TÉLLEZ, F. (2001): Gestión sostenible de paisajes rurales: técnicas e ingeniería. Madrid: Fundación Alfonso Martín Escucro/Mundi, 285 p.

BERTRAND, G. (1993): Lê paisage: um outil pour l'aménagement des territoires em Midi-Pyrinées. France: Conséil Économique est Social Regional de Midi-Pyrénées - CESR, 72 p.

FLATRÈS-MURY, H. (1984): L'evaluation dês paysages bretons, dans lire lê paysages. Université de Saint-Etienne.

GÓMEZ OREA, D. (1985): El espacio rural en la ordenación del territorio. Madrid, Instituto de Estudios Agrários, $540 \mathrm{p}$.

INTERTECHNE CONSULTORES ASSOCIADOS S/C LEME ENGENHARIA LTDA (1992): Estudo de Impacto Ambiental - EIA (Vol. I, II, III, IV). FEAM, Belo Horizonte, MG.

INTERTECHNE CONSULTORES ASSOCIADOS S/C, LEME ENGENHARIA LTDA (1992): Estudo de Impacto Ambiental, EIA. Complementação de informações, $1^{\text {a }}, 2^{\mathrm{a}}$. FEAM, Belo Horizonte, MG.

INTERTECHNE CONSULTORES ASSOCIADOS S/C, LEME ENGENHARIA LTDA (1992): Relatório de Impacto Ambiental, RIMA. FEAM,Belo Horizonte, MG.

LITTON, R.B. JR (1972): Natural environments studies in theoretical and applied analysis. Washington: Library U.S. Forest Service.

MELO CESAR, L.P. (2000): Princípios paisagísticos. 167p. Dissertação (Mestrado em Planejamento Urbano) - Faculdade de Arquitetura e Urbanismo. Universidade de Brasília, Brasília, DF. 


\section{ANEXO \\ Tabla 1 \\ EVALUACIÓN DEL PAISAJE DEL H. FLATRÈS-MURY, 1984³, ADAPTADO POR AYUGA TÉLLEZ (2001)}

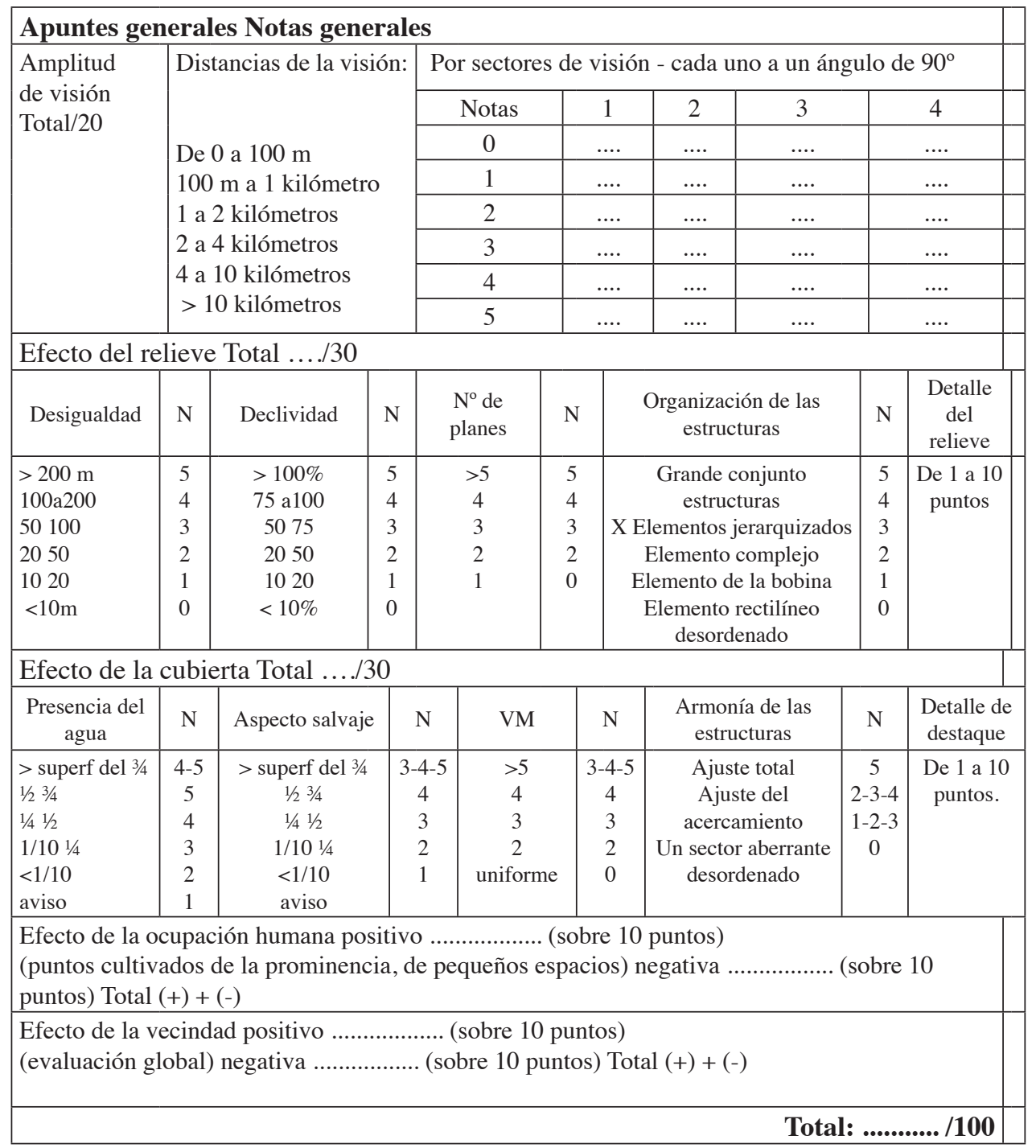

$\mathrm{N}=$ notas; $\mathrm{VM}=$ variedad de masas.

Fuente: Flatres-Mury. L'evaluation dês paysages bretons, dans lire lê paysages. Université de SaintEtienne, 1984. 
Tabla 2

EVALUACIÓN DEL PAISAJE EN EL ENTORNO DEL EMBALSE DEL FUNIL EN EL MUNICIPIO DE IJACI, ADAPTADA DE AYUGA TÉLLEZ, F. (2001)

Lugar fotografiado:

Coordenada

Referencia del paisaje

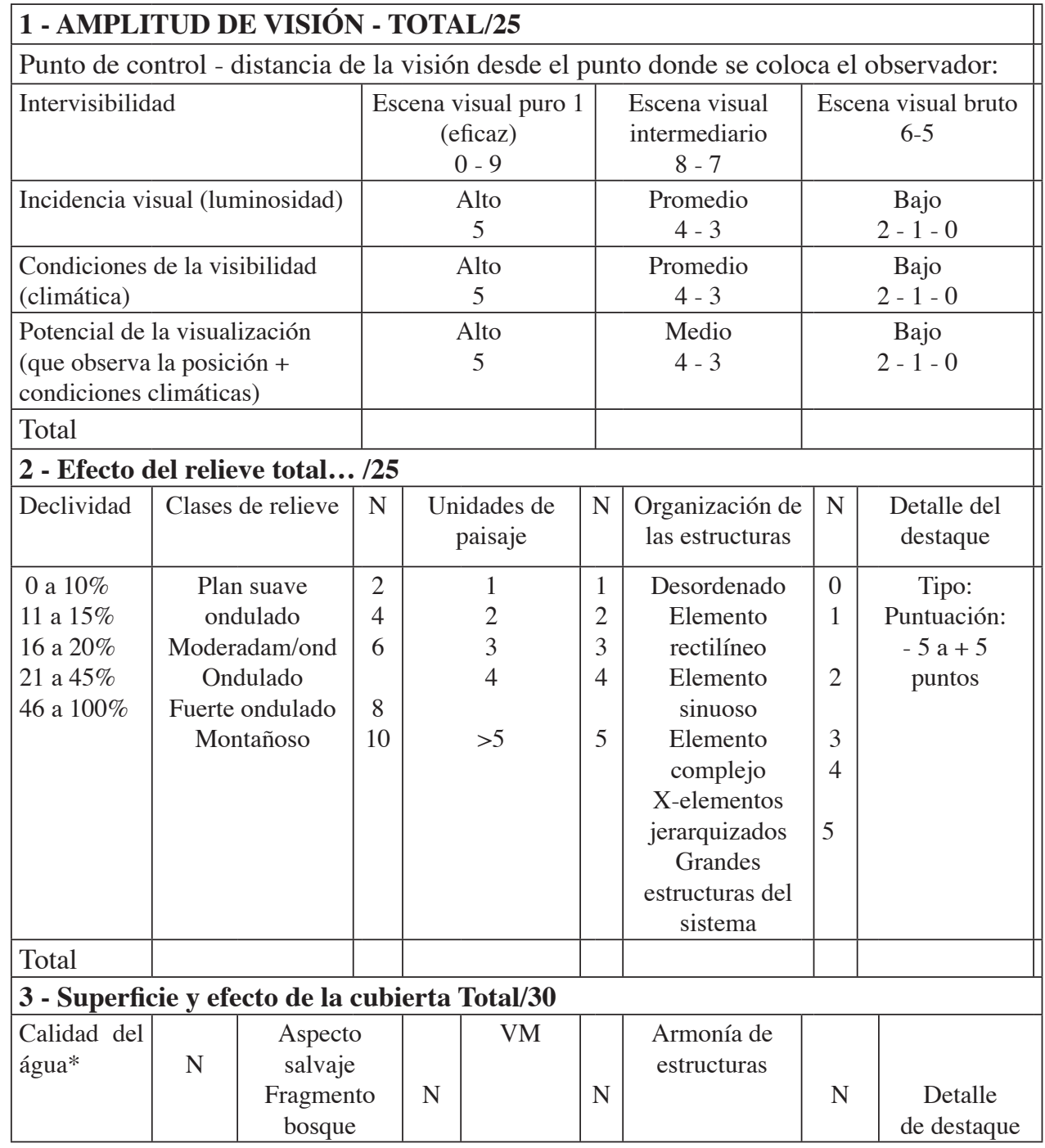




\begin{tabular}{|c|c|c|c|c|c|c|c|c|}
\hline $\begin{array}{l}\text { Índice de } \\
\text { turbidez: } \\
0-10 \text { NTU } \\
11-40 \text { NTU } \\
41-100 \text { NTU } \\
>100 \text { NTU }\end{array}$ & $\begin{array}{c}5-4 \\
3 \\
2 \\
0-1\end{array}$ & $\begin{array}{c}>\text { superficie } \\
\text { del } 3 / 4 \\
1 / 2-3 / 4 \text { del } \\
\text { superf. } \\
1 / 4-1 / 2 \text { del } \\
\text { superf. } \\
1 / 10-1 / 4 \text { del } \\
\text { sup. } \\
<1 / 10 \text { del } \\
\text { superf. } \\
\text { Aviso }\end{array}$ & $\begin{array}{l}4 \\
2 \\
1\end{array}$ & 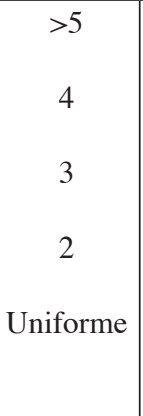 & 2 & 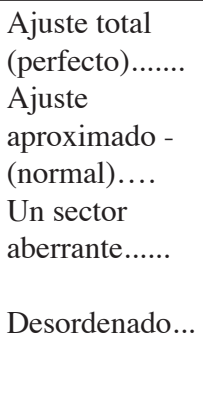 & $\begin{array}{c}4 \\
1-2-3 \\
0\end{array}$ & $\begin{array}{c}\text { Tipo: } \\
\text { Puntuación: - } \\
5 \mathrm{a}+5 \\
\text { puntos }\end{array}$ \\
\hline Total & & & & & & & & \\
\hline
\end{tabular}

Unidad de NTU = de Nephelemetric Turbidit * recolecta de muestras de agua para análisis.

Tabla 2

Continuación...

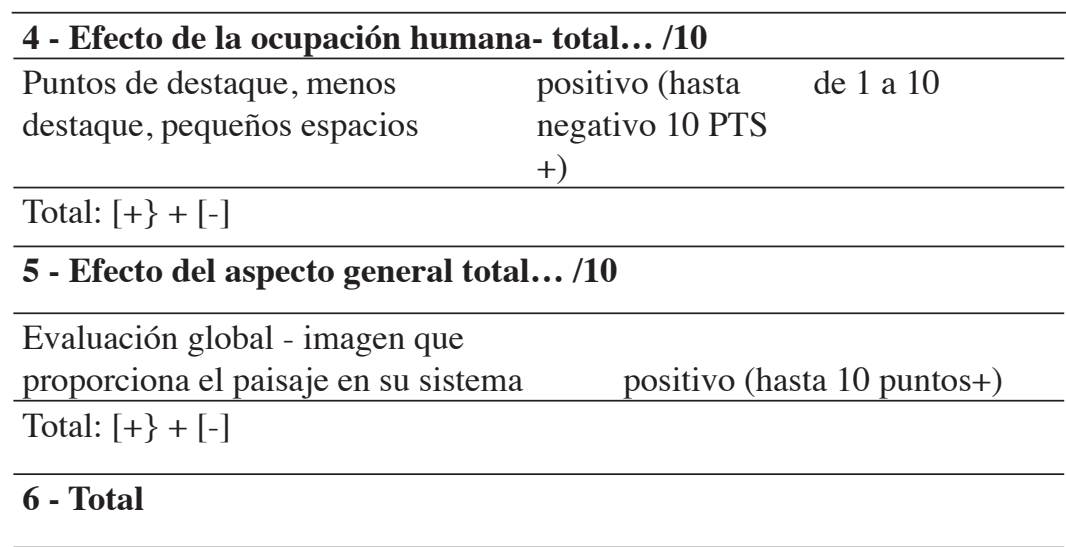

Artículo 1 Artículo 2 Artículo 3 Artículo 4 Artículo 5 Artículo 6 
